\title{
Call for Papers: 2006 IASSIST STRATEGIC PLAN PUBLICATION AWARD
} (Competition is not limited to current IASSIST members)

\author{
Submissions due January 10, 2006 \\ Announcement of winner March 1, 2006 \\ Award: \$250 US and one year membership in IASSIST \\ http://www.iassistdata.org
}

\section{Content focus: Education.}

As an organization, IASSIST has a history of working to educate its members about matters of common professional interest to the social science data community. Traditionally, this education has taken the form of professional development opportunities available in member-initiated and member-taught workshops at the annual IASSIST conference. Yet as the world of social science data grows increasingly complex, staying abreast of new developments in the profession is likely to present an ever increasing challenge for IASSIST members. As a result, the Education Committee of IASSIST is receptive to recommendations for employing new instructional methods and technologies as we strive to meet IASSIST's educational mission.

At its annual conference in May, 2004, the IASSIST membership approved a 5-year Strategic Plan that focuses upon three strategic directions: Education, Outreach, and Advocacy. This paper competition has been established as a means of exploring, articulating, and documenting topical issues related to Education. For further information about the Strategic Plan, see: http://www.iassistdata.org/membership/plan_june2004.pdf

IASSIST seeks papers that address one or more of the issues, principles, and strategies for engagement in the following subject areas:

\section{IASSIST-related Educational Initiatives}

\section{Professional Development and Educational Opportunities of interest to IASSIST members \\ 3. Educational outreach to research communities, including and beyond the social sciences, to promote data preservation and access.}

Papers should include recommendations for action or suggestions of specific projects that can be undertaken (or are underway) to further the education goals of IASSIST.

Prospective submitters may wish to review the discussion on the IASSIST blog about the educational issues arising under the topic of the Accidental Data Librarian (available at http://iassistblog.org/?cat=5). 


\section{IASSIST STRATEGIC PLAN PUBLICATION AWARD}

\section{Criteria for evaluation:}

--relevance of the paper to one or all of the themes in the IASSIST Strategic Plan (specifically Strategic Direction I: Improve and Expand the Educational Component of IASSIST both Internally and Externally.

--inclusion of specific suggestions for action or specific projects that will further the education of IASSIST members or otherwise encourage progress in support of the IASSIST Strategic Plan

--potential in building a base for future IASSIST activity --quality of writing -

-bibliographic content including references to related materials

--clarity in presenting issues and viewpoints as outlined above

\section{Competition details:}

All papers are to be submitted in English.

The winning paper will be announced on the IASSIST list-serve on or around March 1, 2006. In addition to being designated as the winning paper in the IASSIST Quarterly, the author of the winning paper will receive the monetary award and a one-year membership in IASSIST and be recognized at the IASSIST conference in Ann Arbor. All other submissions meeting the criteria for evaluation will be published in the IASSIST Quarterly (IQ) (online and print).

Papers that are submitted to this Strategic Plan Publication Award competition may also be submitted for inclusion in the IASSIST conference in Ann Arbor in May 2006.

Papers must be a minimum of 5 pages in length, including bibliography and graphics as appropriate. We strongly prefer that for publication purposes all documents be submitted in Word format and each graphic be submitted as a separate file in one of the following formats: .gif .jpg .tif .bmp .png

Papers must not have copyright limitations; IASSIST Quarterly (IQ) rights will apply upon publication. All papers must be submitted by January 10, 2006 to the competition web host: David Sheaves

$$
\text { <sheaves@vance.irss.unc.edu> }
$$

Questions (not papers, please) may be sent to:

$$
\text { <iassist-reviews@mailman.srv.ualberta.ca> }
$$

Competition is not limited to current IASSIST members.

The review committee for the IASSIST Strategic Plan Publication Award will be announced on the IASSIST website www.iassistdata.org and on the IASSIST list serve. 